\title{
Patterned Sensory Stimulation Induces Plasticity in Reciprocal Ia Inhibition in Humans
}

\author{
Monica A. Perez, ${ }^{2}$ Edelle C. Field-Fote, ${ }^{2}$ and Mary Kay Floeter ${ }^{1}$ \\ ${ }^{1}$ National Institute of Neurological Disorders and Stroke, National Institutes of Health, Bethesda, Maryland 20892, and ${ }^{2}$ Department of Orthopedics and \\ Rehabilitation, Division of Physical Therapy, and The Miami Project to Cure Paralysis, University of Miami School of Medicine, Miami, Florida 33136
}

\begin{abstract}
Training of spinal cord circuits using sensorimotor stimulation has been proposed as a strategy to improve movement after spinal injury. How sensory stimulation may lead to long-lasting changes is not well understood. We studied whether sensory stimulation might induce changes in the strength of a specific spinal interneuronal circuit: spinally mediated reciprocal Ia inhibition. In healthy humans, the strength of reciprocal inhibition between ankle flexor and extensor muscles was assessed before and after 30 min of peroneal nerve stimulation at motor threshold intensity. Three stimulation protocols were assessed: patterned nerve stimulation (10 pulses at $100 \mathrm{~Hz}$ every $1.5 \mathrm{sec}$ ), uniform nerve stimulation (one pulse every $150 \mathrm{msec}$ ), and combined stimulation of the peroneal nerve and the motor cortex with transcranial magnetic stimulation. Short-latency reciprocal inhibition from ankle flexor to extensor muscles was measured by conditioning the soleus H-reflex with stimulation of the common peroneal nerve. The strength of the reciprocal inhibition was measured at baseline and for $20 \mathrm{~min}$ after each stimulation session. Patterned stimulation, with or without motor cortex stimulation, enhanced reciprocal inhibition for at least $5 \mathrm{~min}$ afterward. The uniform pattern of stimulation was ineffective. These results demonstrate the presence of short-term plasticity within spinal inhibitory circuits. We conclude that the pattern of sensory input is a crucial factor for inducing changes in the spinal circuit for reciprocal inhibition in humans. These findings may have implications for the use of repetitive patterned sensory stimulation in rehabilitative efforts to improve walking ability in patients with spinal injury.
\end{abstract}

Key words: H-reflex; locomotion; transcranial magnetic stimulation; presynaptic inhibition; spinal cord; interneurons

\section{Introduction}

Walking is normally coordinated by networks of interneurons located in the spinal cord (Rossignol, 1996; Burke, 2001). The dynamic flexibility observed during walking arises from modulation of synaptic transmission between neurons in the patterngenerating network (Parker and Grillner, 2000) and from sensory feedback, which modifies the motor pattern (Pearson et al., 1998; Lam and Pearson, 2002). Longer-lasting plasticity in spinal networks has also been demonstrated and has been proposed as a means to permit motor skill learning throughout life (Wolpaw and Tennissen, 2001). Plasticity in spinal networks may be important for motor recovery after spinal cord injury (SCI). After partial spinal injury, treadmill training can gradually improve walking ability in animals and humans (Dietz et al., 1995; Edgerton et al., 1997; Bouyer and Rossignol, 1998; Wernig et al., 1999; Field-Fote, 2001). Treadmill training has a specific benefit on gait (de Leon et al., 1999; Roy et al., 1999), leading to the hypothesis that sensory feedback from the moving legs

\footnotetext{
Received 0ct. 31, 2002; revised Dec. 27, 2002; accepted Dec. 27, 2002.

This work was supported by the National Institute of Neurological Disorders and Stroke intramural program, the National Institutes of Health, and the Department of Health and Human Services. We thank Laura Danielian for her superb assistance with instrumentation, programming, and graphics.

Correspondence should be addressed to Dr. Mary Kay Floeter, EMG Laboratory, National Institute of Neurological Disorders and Stroke, National Institutes of Health, Building 10, Room 5C101, 10 Center Drive, MSC 1404, Bethesda, MD 20892-1404. E-mail: floeter@codon.nih.gov.

Copyright $\odot 2003$ Society for Neuroscience $\quad 0270-6474 / 03 / 232014-05 \$ 15.00 / 0$
}

is a critical factor for training spinal locomotor networks (Pearson, 2000; Edgerton et al., 2001).

If sensory input plays a role in inducing use-dependent plasticity, spinal interneurons that participate in reflex pathways and in locomotor networks would be likely sites for adaptive changes (Pearson, 2000; McCrea, 2001). The Ia inhibitory interneuron, which provides rhythmic inhibitory output from locomotor networks (Pratt and Jordan, 1987) and mediates reciprocal Ia inhibition between antagonist muscles (Hultborn, 1972), is one such candidate. Measures of reciprocal Ia inhibition in humans have shown dynamic modulation during voluntary movements (Crone and Nielsen, 1989; Nielsen et al., 1995). During locomotion, this modulation enhances the alternating pattern of activity between antagonistic muscles (Lavoie et al., 1997; Petersen et al., 1999). Although studies have not directly tested whether a long lasting use-dependent modulation also occurs, the strength of reciprocal Ia inhibition is correlated with the degree and type of physical activity performed by the individual (Nielsen et al., 1993). There are also anecdotal reports that use of a peroneal nerve stimulator appeared to counteract the loss of reciprocal inhibition usually seen in spasticity (Crone et al., 1994).

Our goal was to determine whether sensory stimulation induces plasticity in reciprocal Ia inhibition in intact humans. We hypothesized that stimulation resembling sensory feedback from the foot during stepping would be an effective way to induce plasticity in this circuit. During stepping in animals, the primary afferents of ankle flexor muscles produce a short burst of firing, 
with rates from 100 to $200 \mathrm{~Hz}$ at the beginning of the swing phase (Prochazka and Gorassini, 1998). In this study, the nerve to ankle flexor muscles was stimulated with a short burst ("patterned stimulation") at intervals approximating slow stepping (Auvinet et al., 2002). Patterned stimulation was compared with a uniform pattern of stimulation. To dissociate sensory and motor effects of stimulation, we used electrical stimulation of the nerve just below the intensity needed to produce movement of the foot. Because recent studies in animals have suggested that corticospinal activation may be necessary for induction and maintenance of the plasticity of stretch reflexes (Chen and Wolpaw, 2002), we assessed patterned stimulation combined with concurrent motor cortex activation.

\section{Materials and Methods}

Subjects. Twenty healthy volunteers, $29.4 \pm 7.5$ years ( 13 men, 7 women), without signs or symptoms of neurological disease, participated in the study. The Institutional Review Board approved the protocol, and all subjects signed written informed consent according to the Declaration of Helsinki. Experimental sessions assessed the effects of a $30 \mathrm{~min}$ stimulation paradigm. Subjects participated in multiple sessions separated by at least $2 \mathrm{~d}$.

Stimulation paradigms. Three stimulation paradigms were used to simulate different conditions of sensory feedback from ankle flexor muscles, without producing movement of the foot. (1) "Patterned" nerve stimulation consisted of stimulating the common peroneal nerve (CPN) at the fibular head transcutaneously with a train of 10 pulses (width, 1 $\mathrm{msec})$ at $100 \mathrm{~Hz}$ every $1.5 \mathrm{sec}$ at the intensity of motor threshold $(\sim 1000$ trains). (2) "Combined" stimulation gave patterned stimulation together with transcranial magnetic stimulation (TMS) over the leg area of the motor cortex at an intensity just below threshold for a motor-evoked potential (MEP). TMS was given every $8 \mathrm{sec}$, corresponding to a timing of every fifth step ( $\sim 200$ pairings of TMS and CPN stimulation). (3) "Uniform" stimulation consisted of stimulating the CPN using the same number $(\sim 10,000)$ and intensity of pulses as in the patterned paradigm, but the pulses were uniformly spaced every $150 \mathrm{msec}$. As an additional control, TMS alone was delivered every $8 \mathrm{sec}$ for $30 \mathrm{~min}$ in five subjects.

Outcome measures. Reciprocal inhibition was measured before and up to 20 min after each session. MEPs and long-latency (D1) inhibition of the soleus H-reflex were measured before and 5-10 min after stimulation sessions. Surface EMG was recorded from tibialis anterior (TA) and soleus (SOL) muscles with paired $10 \mathrm{~mm}$ stainless steel disk electrodes using a counterpoint EMG machine (Dantec, Allendale, NJ) with filter bandwidth of $10 \mathrm{~Hz}$ to $2 \mathrm{kHz}$. Waveforms were digitized for off-line analysis using custom software (LabView 5; National Instruments, Austin, TX). Surface EMG from the peroneus longus muscle and the abductor pollicis brevis muscle was monitored during experiments.

Reciprocal inhibition. Reciprocal inhibition was assessed using an SOL $\mathrm{H}$-reflex conditioning-test paradigm. Trials eliciting the test SOL $\mathrm{H}$-reflex were interleaved with trials in which a conditioning stimulus preceded the test SOL H-reflex. Ten conditioned and 10 test H-reflexes were averaged at each time point: before (baseline), immediately after (time 0 ), and at $5 \mathrm{~min}$ intervals up to $20 \mathrm{~min}$ after each stimulation session. The SOL H-reflex was elicited by stimulating the posterior tibial nerve in the popliteal fossa ( $1 \mathrm{msec}$ rectangular pulse) using monopolar stimulation with a remote anode on the patella. Before each session, an H-reflex recruitment curve was obtained. The test SOL H-reflex amplitude was maintained $\sim 15-20 \%$ of $M_{\max }$ for each block of trials (Crone et al., 1990). Conditioning stimulation to the CPN was delivered using bipolar surface electrodes positioned below the fibular head. Motor threshold was defined as a $100 \mu \mathrm{V}$ response of the TA. The CPNstimulating electrode was carefully positioned to avoid activation of peroneus muscles, thus ensuring a more selective stimulation of the deep branch of the peroneal nerve. The optimal interval for stimulating the $\mathrm{CPN}$ to produce disynaptic reciprocal inhibition, either 2 or $3 \mathrm{msec}$, was determined at the beginning of each session and used throughout.

Transcranial magnetic stimulation. A Magstim 200 (Magstim, Dyfed,
UK) was used to elicit MEPs from the TA and SOL muscles. A $70 \mathrm{~mm}$ figure-of-eight coil was used in all but two subjects whose higher thresholds required a double-cone coil to elicit MEPs. The handle of the coil was oriented longitudinally. The position was marked on the scalp, and the coil was clamped in a holder that kept it in the same position throughout testing. MEP thresholds were defined as the lowest intensity to produce MEPs from TA muscles of at least $50 \mu \mathrm{V}$ in 5 of 10 consecutive stimuli at rest without activation of the abductor pollicis brevis muscle. For the combined paradigm, central and peripheral conduction times were estimated using the F wave method (Samii et al., 1998). We calculated the timing of TMS and peripheral nerve stimulation needed to produce synchronous arrival of their volleys at the spinal cord. In most subjects, TMS stimulation was delayed 1-4 msec relative to the CPN stimulation.

MEP recruitment curves at rest were obtained before and 5-10 min after the patterned ( $n=6$ subjects), combined $(n=10)$, and TMS-alone $(n=5)$ sessions. Five MEPs were obtained at each intensity with increments of $5 \%$ stimulator output, beginning at $5 \%$ below motor threshold and ending with maximal stimulator output. MEP areas were measured off-line in individual traces. The mean area for each subject was normalized to the maximal MEP area before the stimulation session.

Long-latency inhibition of soleus H-reflex. Long-latency (D1) inhibition of the SOL H-reflex was tested before and 5-10 min after the patterned $(n=9)$, combined $(n=4)$, and uniform $(n=8)$ stimulation paradigms. The same stimulation and recording set up was used as for testing reciprocal inhibition, except that the conditioning-test intervals were 10 and $15 \mathrm{msec}$. These longer intervals are likely to assess presynaptic inhibition of Ia afferents (Mizuno et al., 1971).

Dorsiflexion movement of the foot. Movement of the foot was videotaped during stimulation sessions. Markers were positioned on anatomical landmarks to measure the dorsiflexion movement produced by the stimulation paradigms. In most sessions, no movement occurred, but, in a few sessions, slight dorsiflexion of no more than $4^{\circ}$ occurred.

Statistical analysis. A two-factor ANOVA, assessing the factors of stimulation paradigm (three levels) and testing time (six time points: baseline and five poststimulation time points), was used to analyze the effects of stimulation sessions on reciprocal inhibition between groups of subjects. A two-factor repeated-measures ANOVA was used to assess effects on and long-latency (D1) inhibition, and a three-factor ANOVA was used to assess MEP recruitment curves (intensity $\times$ paradigm $\times$ time). A onefactor ANOVA was used to analyze the effects of TMS alone on reciprocal inhibition. Post hoc testing to determine significant comparisons was done using a criterion of $p<0.05$ with correction for multiple comparisons. Additionally repeated-measures ANOVA were analyzed for the subset of 15 subjects who participated in multiple stimulation paradigms, and their results were consistent with the group analysis.

\section{Results}

\section{Reciprocal inhibition}

Reciprocal inhibition was increased by the stimulation sessions compared with baseline (two-factor ANOVA; $F=6.22 ; p=$ 0.002 ; df $=2,5)$ (Fig. 1). Post hoc testing revealed that both patterned $(p=0.0008 ; n=18)$ and combined $(p=0.001 ; n=$ $14)$ stimulation paradigms were effective at strengthening reciprocal inhibition but that the uniform stimulation was not $(p=$ $0.92 ; n=8)$. At baseline, reciprocal inhibition produced a $12-$ $15 \%$ inhibition of the test SOL H-reflex size. Immediately after stimulation, reciprocal inhibition increased to $17 \%$ in the patterned paradigm but was unchanged in the combined and slightly decreased $(5 \%)$ in the uniform paradigm. Five minutes after stimulation, reciprocal inhibition increased to $22 \%$ in the patterned and combined paradigms but remained the same in the uniform (5\%) paradigm (Figs. 1, 2). The effect was short lived, however, and, by $10 \mathrm{~min}$, reciprocal inhibition began declining and had returned to baseline by $20 \mathrm{~min}$. The effects of stimulation were not explained by differences in the test SOL H-reflex size, which was maintained at the same target amplitude throughout the study, and was similar in all stimulation protocols (14.6 \pm 


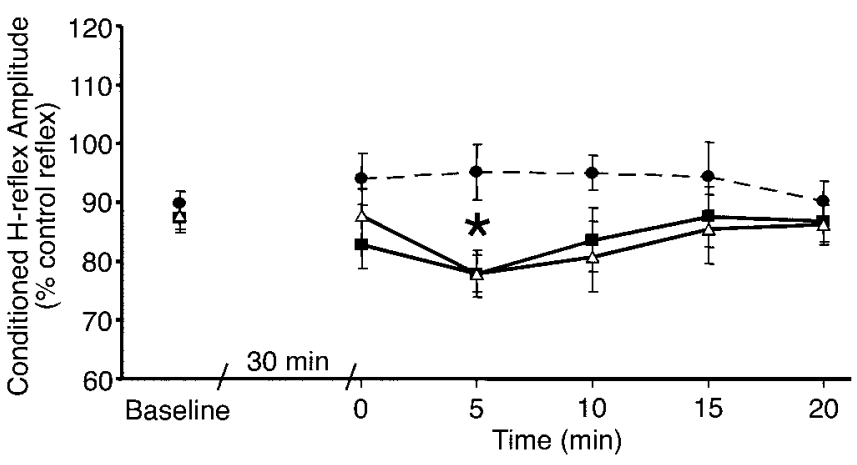

Figure 1. Effect of stimulation paradigms on reciprocal inhibition of the SOL H-reflex. Ten test and 10 conditioned reflexes were averaged at each time point for each subject. Group means and SEs are plotted before and after the patterned (triangles; $n=18$ ), combined (squares; $n=14$ ), and uniform (circles with dashed line; $n=8$ ) stimulation sessions. ${ }^{*} p<0.01$ indicates interval identified in post hoc testing as significantly different from baseline (Fishers test).

\section{Test H-reflex}
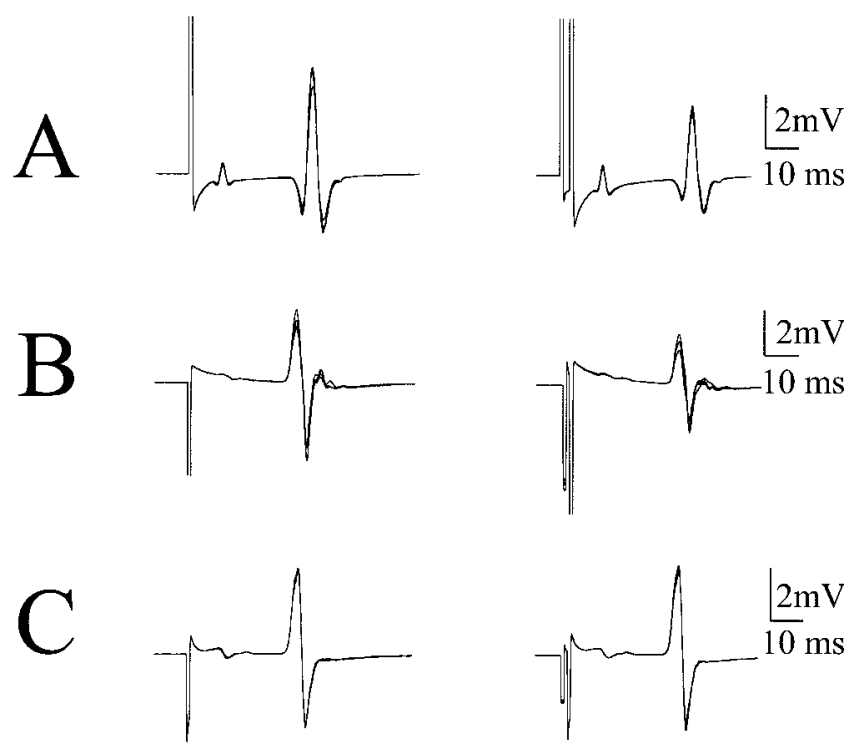

Figure 2. Reciprocal inhibition. Examples of test and conditioned SOL H-reflexes 5 min after stimulation sessions; five traces are superimposed in each panel. Data are from three subjects. $A$, Patterned; $B$, combined; $C$, uniform paradigms.

$4.1 \%$ of $M_{\max }$ in the patterned stimulation paradigm; $11.7 \pm 3.4$ of $M_{\max }$ in the combined stimulation paradigm; and $12.9 \pm 2.5 \%$ of $M_{\max }$ in the uniform stimulation paradigms). In addition, TMS alone was not effective at strengthening reciprocal inhibition (one-factor ANOVA; $F=0.04 ; p=0.98 ; n=5$ ).

\section{Cortical excitability}

MEP recruitment curves were unchanged before and after the stimulation sessions and were similar for TA and SOL muscles, as shown in Figure 3. There was no difference in the MEP areas before and after stimulation sessions (three-factor ANOVA; SOL, $F=1.333, p=0.26, \mathrm{df}=2,1,7$; TA, $F=2.397, p=0.09, \mathrm{df}=2$, $1,7)$. A trend for larger MEPs after the combined stimulation paradigm at the highest intensities $(>20 \%$ above motor threshold) was seen only in the three subjects with motor thresholds low enough to assess these high intensities.

\section{Long-latency (D1) inhibition}

Long-latency (D1) inhibition produced a 10\% decline in the SOL H-reflex at baseline. Two-factor ANOVA showed no effect of stimulation on long-latency (D1) inhibition at 5-10 min after stimulation $(F=0.76 ; p=0.47 ; \mathrm{df}=2,1)$ (Fig. 4$)$.

\section{Discussion}

The pattern of sensory input is critical

We found that the strength of reciprocal Ia inhibition between ankle flexor and extensor muscles could be temporarily increased by stimulating the CPN for $30 \mathrm{~min}$ in normal human subjects. Nerve stimulation did not need to produce movements of the foot to be effective. However, the temporal pattern of stimulation was critical. Patterned stimulation in rhythmic bursts was effective, whereas a uniform pattern of stimulation was ineffective. The patterned stimulation mimicked aspects of the sensory feedback from muscle spindles during stepping. The pulse train of $100 \mathrm{~Hz}$ was chosen because the firing rate of Ia afferents of ankle dorsiflexor muscles increases up to $100-200 \mathrm{~Hz}$ during the swing phase of locomotion, as the muscles contract briefly to lift the foot (Prochazka and Gorassini, 1998). The interval of $1.5 \mathrm{sec}$ is slightly slower than the stepping speed of healthy individuals (Auvinet et al., 2002), but other aspects of the patterned stimulation were highly artificial, such as synchronous activation of afferents, lack of frequency modulation within pulse trains, and absence of associated changes in muscle velocity, length, and joint angles. Although this stimulation was sufficient to induce changes in spinally mediated reciprocal inhibition, it is likely that the optimal stimulation for training spinal locomotor circuits will involve the more complex mixture of afferent signals that are naturally produced by the stepping movement (Pearson et al., 1998; Lam and Pearson, 2002).

Patterned nerve stimulation was effective in inducing, but not in maintaining, plasticity in reciprocal Ia inhibition. Other investigators have proposed that corticospinal input plays a permissive role in the induction and maintenance of plasticity of stretch reflexes (Chen and Wolpaw, 2002). We expected that combining motor cortex stimulation with patterned nerve stimulation would prolong plastic changes, but this did not occur. It may be that a different intensity or timing of TMS, or the use of repetitive trains of TMS is needed. We used intensities of TMS that have been shown to produce corticospinal volleys in invasive human studies (Houlden et al., 1999) and calculated the timing between nerve and TMS stimulation so that the volleys would arrive synchronously at the spinal cord. Synchronous timing between the arrival of sensory volleys at the cortex and TMS has been shown to be critical for inducing plasticity in the motor cortex (Stefan et al., 2000; McKay et al., 2002).

Although descending corticospinal inputs can modulate transmission in the Ia interneuron (Hultborn, 1972), several lines of evidence suggest that the effects in this experiment did not occur in the motor cortex. First, the MEP recruitment curves were unchanged by patterned and combined stimulation. Previous studies have shown that sensory stimulation necessary to produce motor cortex plasticity is either twofold to threefold stronger than in this study (Khaslavskaia et al., 2002) or given for longer periods (Ridding et al., 2001; McKay et al., 2002), or synchronized to arrive simultaneously when TMS is delivered to the motor cortex (Stefan et al., 2000). Our data are in agreement with reports showing no change in TA MEPs after $30 \mathrm{~min}$ of CPN stimulation at motor threshold intensity (Khaslavskaia et al., 2002). 

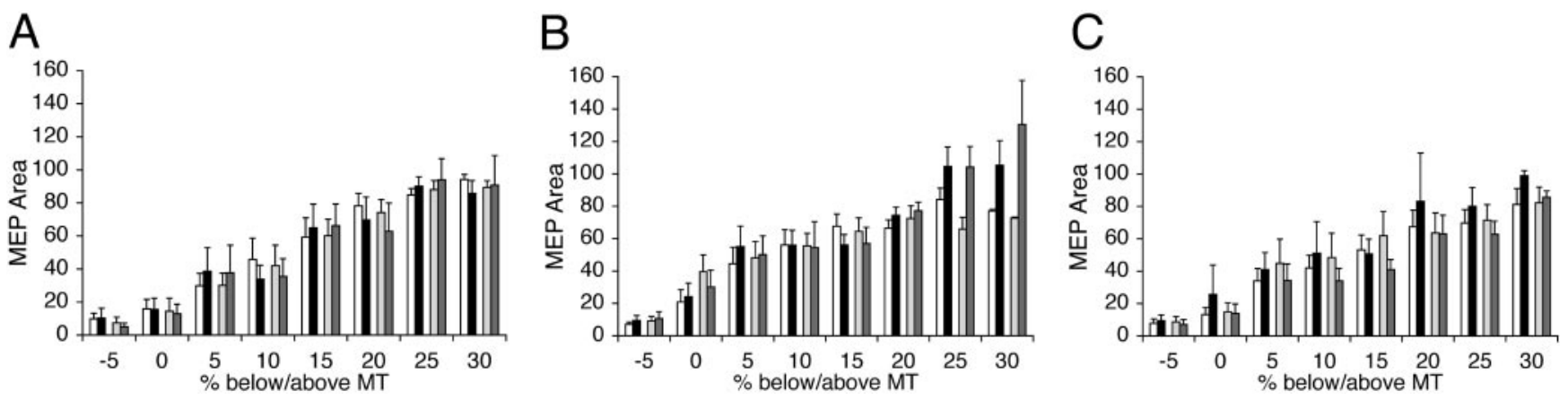

Figure 3. Effect of stimulation sessions on TA and SOL MEP recruitment curves. MEP areas before (SOL, white; TA, light gray) and after (SOL, black; TA, dark gray) participation in the patterned (A; $n=6)$, combined $(B ; n=10)$, and TMS-alone $(C ; n=5)$ stimulation sessions. Error bars indicate group means with SEs. TMS intensity is expressed on the $x$-axis as percentage of stimulator output relative to motor threshold (MT).

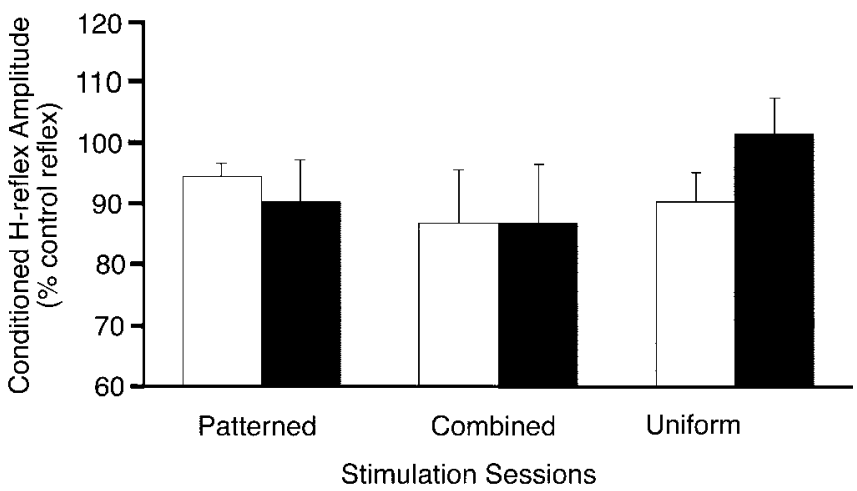

Figure 4. Long-latency (D1) inhibition. Inhibition of the SOL H-reflex by conditioning stimulation of the (PN at 10-15 msec conditioning-test interval. Group means and SEs are plotted for all subjects before (white bars) and after (black bars) stimulation sessions.

\section{Possible neural mechanisms involved in changes of reciprocal inhibition}

The increased strength of reciprocal inhibition could be attributable to changes in one of several sites along the disynaptic circuit. The inhibitory synapse on the motor neuron could itself be potentiated, as has been shown with synaptic transmission of glycinergic synapses in the goldfish in response to short tetanic trains (Korn et al., 1992; Oda et al., 1995) and for GABAmediated inhibitory synapses in cerebellar Purkinje cells (Kano et al., 1992). Alternatively, greater excitability of the Ia interneuron pool could recruit subliminal interneurons or "latent" inhibitory connections (Charpier et al., 1995; Oda et al., 1995). Potentiation of the glutamatergic Ia afferent synapse on the Ia interneuron is also a possibility, although we did not see changes in long-latency (D1) inhibition, which is activated by the same Ia afferent fibers, when tested 5-10 min after stimulation.

\section{Implications for rehabilitation after SCI}

By showing that sensory stimulation can increase the strength of reciprocal inhibition in intact humans, this study offers a potential category of mechanisms that could underlie the effects of sensorimotor stimulation in rehabilitation. In humans with incomplete SCI, spinal inhibitory reflexes mediated by GABA and glycine are reduced (Calancie et al., 1993; Boorman et al., 1996; Okuma et al., 2002). Reduction in disynaptic glycinergic reciprocal Ia inhibition is thought to contribute to abnormal muscle coactivation during locomotion (Fung and Barbeau, 1989). Rehabilitative strategies to improve locomotion using intensive treadmill training (Dietz et al., 1995; Wernig et al., 1999; Field-
Fote, 2001) demonstrate a reduced co-contraction and improved alternation between antagonistic muscles (Dietz et al., 1995; Harkema et al., 1997). Our study suggests that training could exert its effects by strengthening specific spinal circuits, such as reciprocal inhibition, that are activated by sensory feedback.

Paradoxically, markers of glycinergic and GABAergic synapses are increased in spinalized animals (for review, see Edgerton et al., 2001). Step training reduces GABAergic (Tillakaratne et al., 2000) and glycinergic (de Leon et al., 1999) markers in the lumbar spinal cord, as well as motor responses to strychnine, a glycinergic antagonist. These findings may raise doubts about the utility of strengthening inhibitory reflexes in humans with SCI. However, a recent animal study found that training reduced inhibitory synapses differentially on those motor neurons innervating muscles that were activated during the step training (Tillakaratne et al., 2002). Thus, changes in transmission in spinal inhibitory pathways may occur in an activity-dependent manner.

Understanding the parameters that can best modify spinal interneuronal networks is one key to optimizing rehabilitation strategies. Our study looked at the effects of a single stimulation session and a single spinal reflex circuit. Locomotor training for rehabilitation clearly provides a more complex experience than provided by the stimulation in this study. Future studies will need to determine the role of this multisensory signal and of repeated sessions in inducing progressive changes in spinal circuits.

\section{References}

Auvinet B, Berrut G, Touzard C, Moutel L, Collet N, Chaleil D, Barrey E (2002) Reference data for normal subjects obtained with an accelerometric device. Gait Posture 16:124-134.

Boorman GI, Lee RG, Becker WJ, Windhorst UR (1996) Impaired "natural reciprocal inhibition" in patients with spasticity due to incomplete spinal cord injury. Electroencephalogr Clin Neurophysiol 101:84-92.

Bouyer LJ, Rossignol S (1998) The contribution of cutaneous inputs to locomotion in the intact and the spinal cat. Ann NY Acad Sci 860:508-512.

Burke RE (2001) The central pattern generator for locomotion in mammals. Adv Neurol 87:11-24.

Calancie B, Broton JG, Klose KJ, Traad M, Difini J, Ayyar DR (1993) Evidence that alterations in presynaptic inhibition contribute to segmental hypo- and hyperexcitability after spinal cord injury in man. Electroencephalogr Clin Neurophysiol 89:177-186.

Charpier S, Behrends JC, Triller A, Faber DS, Korn H (1995) "Latent" inhibitory connections become functional during activity-dependent plasticity. Proc Natl Acad Sci USA 92:117-120.

Chen XY, Wolpaw JR (2002) Probable corticospinal tract control of spinal cord plasticity in the rat. J Neurophysiol 87:645-652.

Crone C, Nielsen J, Petersen N, Ballegaard M, Hultborn H (1994) Disynaptic reciprocal inhibition of ankle extensors in spastic patients. Brain 117:1161-1168.

Crone C, Hultborn H, Mazieres L, Morin C, Nielsen J, Pierrot-Deseilligny E 
(1990) Sensitivity of monosynaptic test reflexes to facilitation and inhibition as a function of the test reflex size: a study in man and the cat. Exp Brain Res 81:35-45.

Crone C, Nielsen J (1989) Spinal mechanisms in man contributing to reciprocal inhibition during voluntary dorsiflexion of the foot. J Physiol (Lond) 416:255-272.

de Leon RD, Tamaki H, Hodgson JA, Roy RR, Edgerton VR (1999) Hindlimb locomotor and postural training modulates glycinergic inhibition in the spinal cord of the adult spinal cat. J Neurophysiol 82:359-369.

Dietz V, Colombo G, Jensen L, Baumgartner L (1995) Locomotor capacity of spinal cord in paraplegic patients. Ann Neurol 37:574-582.

Edgerton VR, de Leon RD, Harkema SJ, Hodgson JA, London N, Reinkensmeyer DJ, Roy RR, Talmadge RJ, Tillakaratne NJ, Timoszyk W, Tobin A (2001) Retraining the injured spinal cord. J Physiol (Lond) 533:15-22.

Edgerton VR, de Leon RD, Tillakaratne N, Recktenwald MR, Hodgson JA, Roy RR (1997) Use-dependent plasticity in spinal stepping and standing. Adv Neurol 72:233-247.

Field-Fote EC (2001) Combined use of body weight support, functional electric stimulation, and treadmill training to improve walking ability in individuals with chronic incomplete spinal cord injury. Arch Phys Med Rehabil 82:818-824.

Fung J, Barbeau H (1989) A dynamic EMG profile index to quantify muscular activation disorder in spastic paretic gait. Electroencephalogr Clin Neurophysiol 73:233-244.

Harkema SJ, Hurley SL, Patel UK, Requejo PS, Dobkin BH, Edgerton VR (1997) Human lumbosacral spinal cord interprets loading during stepping. J Neurophysiol 77:797-811.

Houlden DA, Schwartz ML, Tator CH, Ashby P, MacKay WA (1999) Spinal cord-evoked potentials and muscle responses evoked by transcranial magnetic stimulation in 10 awake human subjects. J Neurosci 19:1855-1862.

Hultborn H (1972) Convergence on interneurones in the reciprocal Ia inhibitory pathway to motoneurones. Acta Physiol Scand Suppl 375:1-42.

Kano M, Rexhausen U, Dreessen J, Konnerth A (1992) Synaptic excitation produces a long-lasting rebound potentiation of inhibitory synaptic signals in cerebellar Purkinje cells. Nature 356:601-604.

Khaslavskaia S, Ladouceur M, Sinkjaer T (2002) Increase in tibialis anterior motor cortex excitability following repetitive electrical stimulation of the common peroneal nerve. Exp Brain Res 145:309-315.

Korn H, Oda Y, Faber DS (1992) Long-term potentiation of inhibitory circuits and synapses in the central nervous system. Proc Natl Acad Sci USA 89:440-443.

Lam T, Pearson KG (2002) The role of proprioceptive feedback in the regulation and adaptation of locomotor activity. Adv Exp Med Biol 508:343-355.

Lavoie BA, Devanne H, Capaday C (1997) Differential control of reciprocal inhibition during walking versus postural and voluntary motor tasks in humans. J Neurophysiol 78:429-438.

McCrea DA (2001) Spinal circuitry of sensorimotor control of locomotion. J Physiol (Lond) 533:41-50.

McKay DR, Ridding MC, Thompson PD, Miles TS (2002) Induction of persistent changes in the organisation of the human motor cortex. Exp Brain Res 143:342-349.

Mizuno Y, Tanaka R, Yanagisawa N (1971) Reciprocal group I inhibition on triceps surae motoneurons in man. J Neurophysiol 34:1010-1017.
Nielsen J, Crone C, Sinkjaer T, Toft E, Hultborn H (1995) Central control of reciprocal inhibition during fictive dorsiflexion in man. Exp Brain Res 104:99-106.

Nielsen J, Crone C, Hultborn H (1993) H-reflexes are smaller in dancers from The Royal Danish Ballet than in well trained athletes. Eur J Appl Physiol 66:116-121.

Oda Y, Charpier S, Murayama Y, Suma C, Korn H (1995) Long-term potentiation of glycinergic inhibitory synaptic transmission. J Neurophysiol 74:1056-1074.

Okuma Y, Mizuno Y, Lee RG (2002) Reciprocal Ia inhibition in patients with asymmetric spinal spasticity. Clin Neurophysiol 113:292-297.

Parker D, Grillner S (2000) Neuronal mechanisms of synaptic and network plasticity in the lamprey spinal cord. Prog Brain Res 125:381-398.

Pearson KG (2000) Plasticity of neuronal networks in the spinal cord: modifications in response to altered sensory input. Prog Brain Res 128:61-70.

Pearson KG, Misiaszek JE, Fouad K (1998) Enhancement and resetting of locomotor activity by muscle afferents. Ann NY Acad Sci 860:203-215.

Petersen N, Morita H, Nielsen J (1999) Modulation of reciprocal inhibition between ankle extensors and flexors during walking in man. J Physiol (Lond) 520:605-619.

Pratt CA, Jordan LM (1987) Ia inhibitory interneurons and Renshaw cells as contributors to the spinal mechanisms of fictive locomotion. J Neurophysiol 57:56-71.

Prochazka A, Gorassini M (1998) Ensemble firing of muscle afferents recorded during normal locomotion in cats. J Physiol (Lond) 507:293-304.

Ridding MC, McKay DR, Thompson PD, Miles TS (2001) Changes in corticomotor representations induced by prolonged peripheral nerve stimulation in humans. Clin Neurophysiol 112:1461-1469.

Rossignol S (1996) Neural control of stereotypic limb movements. In: Handbook of physiology, Sec 12, Exercise: regulation and integration of multiple systems, (Rowell L, Shepherd J, ed), pp 173-216. New York: American Physiological Society.

Roy RR, Ishihara A, Kim JA, Lee M, Fox K, Edgerton VR (1999) Metabolic and morphological stability of motoneurons in response to chronically elevated neuromuscular activity. Neuroscience 92:361-366.

Samii A, Luciano CA, Dambrosia JM, Hallett M (1998) Central motor conduction time: reproducibility and discomfort of different methods. Muscle Nerve 21:1445-1450.

Stefan K, Kunesch E, Cohen LG, Benecke R, Classen J (2000) Induction of plasticity in the human motor cortex by paired associative stimulation. Brain 123:572-584.

Tillakaratne NJK, de Leon RD, Hoang TX, Roy RR, Edgerton VR, Tobin AJ (2002) Use-dependent modulation of inhibitory capacity in the feline lumbar spinal cord. J Neurosci 22:3130-3143.

Tillakaratne NJ, Mouria M, Ziv NB, Roy RR, Edgerton VR, Tobin AJ (2000) Increased expression of glutamate decarboxylase $(\operatorname{GAD}(67))$ in feline lumbar spinal cord after complete thoracic spinal cord transection. J Neurosci Res 60:219-230.

Wernig A, Nanassy A, Muller S (1999) Laufband (treadmill) therapy in incomplete paraplegia and tetraplegia. J Neurotrauma 16:719-726.

Wolpaw JR, Tennissen AM (2001) Activity-dependent spinal cord plasticity in health and disease. Annu Rev Neurosci 24:807-843. 